\title{
Multiple-Load Induction Cooking Application with Three-Leg Inverter Configuration
}

\author{
P. Sharath Kumar ${ }^{\dagger}$, N. Vishwanathan*, and Bhagwan K. Murthy* \\ †.* Department of Electrical Engineering, National Institute of Technology Warangal, Telangana, India
}

\begin{abstract}
Inverter configurations for multiple-load induction cooking applications need development. Inverter configurations for induction cooking applications are used in home appliances based on single coil inverters. For multiple-load configurations, multiple coils are used. They require proper inverters, which provide independent control for each load and have fewer components. This paper presents a three-leg inverter configuration for three load induction cooking applications. Each induction coil powers one induction cooking load. This configuration operates with constant switching frequency and powers individual loads. The output power of the required load is controlled with a phase-shift control technique. This configuration is simulated and experimentally tested with three induction loads. The simulation and experimental results are in good agreement. This configuration can be extended to more loads.
\end{abstract}

Key words: Induction cooking, Multiple-loads, Phase shift control

\section{INTRODUCTION}

Induction cooking is one of the applications of induction heating. Conventionally, heating of any object involves the transfer of heat from the heat source to the object heated by conduction or radiation. The method of induction heating involves the development of heat directly in the object heated. A high frequency alternating current flowing through a coil wound over the object induces eddy currents in it. These eddy currents result in $\mathrm{I}^{2} \mathrm{R}$ losses in the object and result in heating. Fig. 1 shows the typical arrangement of a high frequency induction heating circuit.

A resonant inverter is commonly used as a source of high frequency AC supply. DC input is derived by rectifying the utility AC source. High frequency AC flowing in the load coil results in eddy currents induced in the vessel at skin depth level resulting in a heating effect. The heat generated by the eddy currents in the load is concentrated in a peripheral layer at skin depth $(\delta)$ [1], which is expressed as

$$
\delta=\sqrt{\frac{\rho}{\pi \mu f_{s}}}=\sqrt{\frac{1}{4 \pi^{2} \times 10^{-7}}} \times \sqrt{\frac{\rho}{\mu_{r} f_{s}}}
$$

Manuscript received Apr. 1, 2015; accepted Apr. 13, 2015

Recommended for publication by Associate Editor Jee-Hoon Jung.

'Corresponding Author: sharathpapani@nitw.ac.in

Tel: +91-8801067027, National Institute of Technology Warangal

*Department of Electrical Engineering, National Institute of Technology Warangal, India where, $\rho$ is electrical resistivity, $\mu$ is magnetic permeability, $\mu_{\mathrm{r}}$ is the relative magnetic permeability of the load material, and $f_{s}$ is the switching frequency of the inverter.

The high frequency alternating current is induced by a high frequency inverter. The frequency of the alternating current is decided by the material of the heated vessel. The vessels may be composed of either magnetic or non-magnetic material. Based on this, the range of frequency for induction cooking is $20 \mathrm{kHz}$ to $150 \mathrm{kHz}$. These are resonated with a capacitor because of the inherently low power factor of the induction-heating load. Hence, series resonant inverters are the common choice for high-frequency induction cooking systems. Commonly preferred configurations are quasi-resonant, half-bridge, and full-bridge resonant inverters [1]-[4], [19]. Half-bridge configuration is mostly preferred, whereas for high power applications, full-bridge configuration may be used. The control of the output power of these resonant inverters can be achieved through certain methods, such as pulse amplitude modulation (PAM), pulse frequency modulation (PFM), phase-shift (PS) control, asymmetric voltage cancellation (AVC), asymmetric duty cycle (ADC) control, and hybrid control technique [5]-[11], [25]. These control techniques have their relative merits and demerits.

Multiple-load induction cooking systems are in focus for suitable inverter configurations. The main function of 


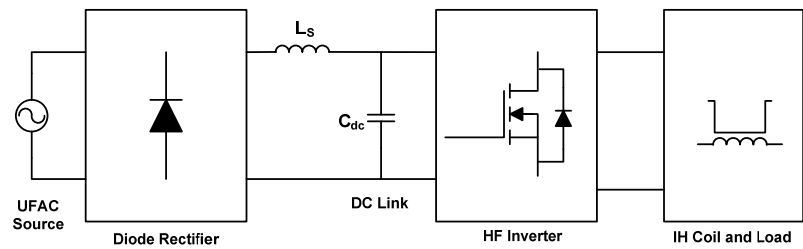

Fig. 1. Typical arrangement of an induction cooking resonant inverter.

inverters in multiple-load induction cooking systems is to reduce components count, simultaneous and independent control of each load, and high conversion efficiency. An inverter with two loads is proposed and analyzed in [12]. This method has one master and one slave load, and uses several resonant capacitors connected in parallel with electro-mechanical switches. The control of load power is achieved by activating these electro-mechanical switches. The disadvantages of this method are a large number of capacitors and use of electro-mechanical switches. An inverter configuration for two-loads is presented in [13], which has three legs (six switching devices). One leg of the inverter is common for both loads, and offers independent control of each load with high efficiency. It also offers a reduced component count and better device utilization. AVC control technique is adopted for power control. In [14], a two-output induction cooking system with power factor correction is proposed. Power control for each load is performed using the AVC control technique. In [15], a load-adaptive control algorithm is used for variable load and large output power range. Aspects such as efficiency, acoustic noise, and flicker control are considered in the design stage. For different ranges of output power, different control techniques are adopted. Though certain objectives are met, it makes the control structure more involved. To improve light-load performance, discontinuous conduction mode control is adopted in [16], and uses variable frequencies in the range $20 \mathrm{kHz}$ to $150 \mathrm{kHz}$. It improves light load efficiency to $95 \%$, but variable frequency operation is the limitation of this technique. The digital implementation of induction heating load is proposed in [17]. An AC-AC power conversion technique is presented in [18] for a multiple induction heating system. It has higher efficiency, a reduced components count, and reduced complexity, however uses variable frequency control, which is the limitation of this method.

In the above-mentioned literature for multiple-load application, either the inverters have a larger components count or variable frequency control is adopted. Enough scope exits in this area for further improvement with constant frequency control and reduced complexity. In this paper, a three-leg inverter configuration is presented for a three-load induction cooking system. It offers constant switching frequency operation, simple control, less components count, and high efficiency.

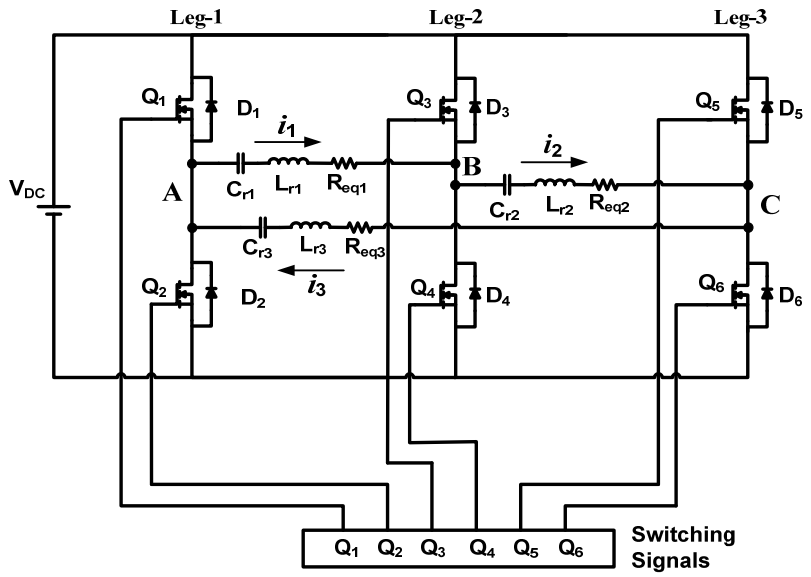

Fig. 2. Three-leg inverter configuration.

This paper is organized as follows. In Section II, principle of operation of three-leg inverter configuration is presented. Section III describes the simulation and experimental results. Section IV presents characteristics showing power control of loads. Section V presents extension of this configuration to more than three loads. Section VI concludes the paper.

\section{THREE-LEG INVERTER CONFIGURATION AND CONTROL SCHEME}

This section describes the inverter configuration and control scheme for a three-load induction cooking application. Fig. 2 shows the circuit diagram of this configuration. Fig. 3 shows only load resonant tank circuits, where three loads are connected in delta across inverter output voltages $v_{\mathrm{AB}}, v_{\mathrm{BC}}$, and $v_{\mathrm{CA}}$.

An induction cooking system consists of a vessel and an induction coil. The coil and vessel are similar to the primary and secondary of a transformer. Based on this, induction cooking load in referrence to the coil is modeled as a series $R_{e q}-L_{r}$ circuit for constant switching frequency operation [12], [20]-[24]. $R_{e q}$ is the referred equivalent resistance and $L_{r}$ is the referred equivalent inductance to the coil, respectively.

The concept of series resonance is used with each load. The resonant load circuits are connected in delta at the output terminals of the inverter configuration. They are marked as leg-1, leg-2, and leg-3. Load-1 consists of $\mathrm{C}_{\mathrm{rl}}, \mathrm{L}_{\mathrm{rl}}$, and $\mathrm{R}_{\mathrm{eq} 1}$, which are resonant capacitor, inductance of the load-1, and equivalent load resistance in series with resonant tank, respectively. For load-2, $\mathrm{C}_{\mathrm{r} 2}, \mathrm{~L}_{\mathrm{r} 2}$, and $\mathrm{R}_{\mathrm{eq} 2}$ are the resonant capacitor, inductance of the load-2, and equivalent load resistance in series with resonant tank, respectively. Similarly for load-3, $\mathrm{C}_{\mathrm{r} 3}, \mathrm{~L}_{\mathrm{r} 3}$, and $\mathrm{R}_{\mathrm{eq} 3}$ are the resonant capacitor, inductance of the load-3, and equivalent load resistance in series with resonant tank, respectively.

Under an equal maximum output power of all loads, the inverter is switched at $30 \mathrm{kHz}$ and the gate pulses of each leg are phase shifted by $120^{\circ}$ w. r. t. other leg pulses. All 


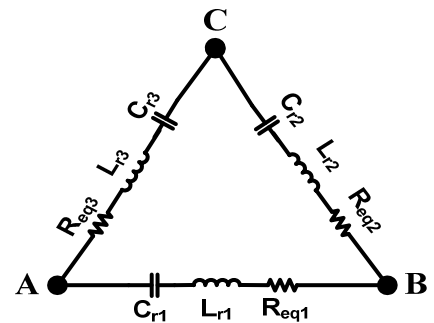

Fig. 3. Three load resonant circuit.

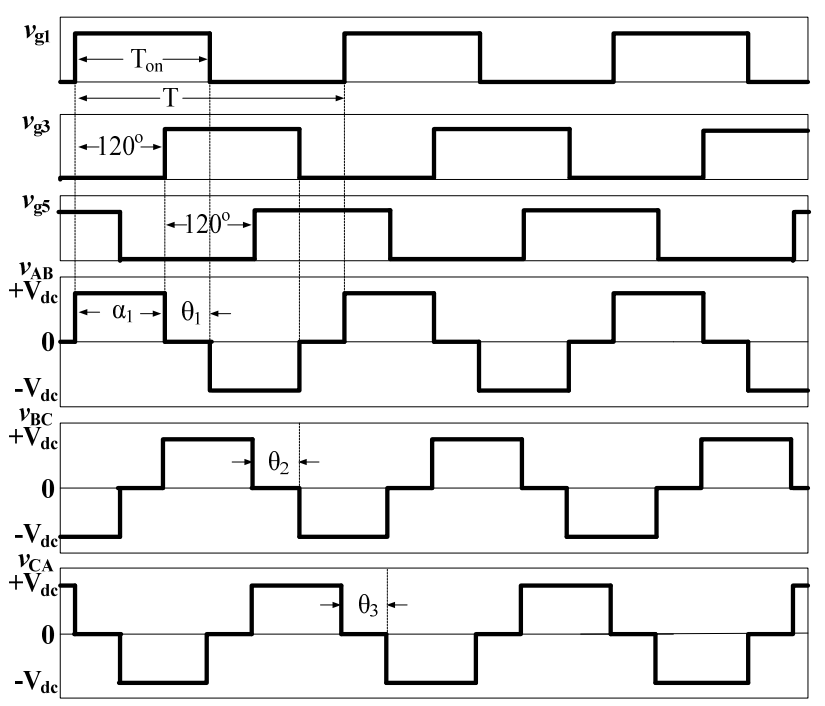

Fig. 4. Inverter gate pulses and output voltage waveforms $v_{\mathrm{AB}}$, $v_{\mathrm{BC}}$, and $v_{\mathrm{CA}}$.

three-load circuits have the same component values and all inverter legs are operated at the same switching frequency. Hence, the resonant frequencies of all load circuits have to be the same. The resonant frequency of each load circuit is $\mathrm{f}_{\mathrm{r}}=\frac{1}{2 \pi \sqrt{L_{r} C_{r}}}$. The switching frequency of each leg is slightly higher than their resonant frequency. The inverter switching frequency $\left(f_{s}\right)$ is chosen at $5 \%$ to $10 \%$ higher than the resonant frequency $\left(f_{r}\right)$ for ZVS operation.

In this configuration, the duty-ratio of the gate pulses is kept constant. Fig. 4 shows the gate pulses $v_{\mathrm{g} 1}, v_{\mathrm{g} 3}$, and $v_{\mathrm{g} 5}$ for the switching devices $\mathrm{Q}_{1}, \mathrm{Q}_{3}$, and $\mathrm{Q}_{5}$, respectively. These are $120^{\circ}$ phase shifted with each other. The gate pulses of $\mathrm{Q}_{2}, \mathrm{Q}_{4}$, and $\mathrm{Q}_{6}$ are $180^{\circ}$ out of phase w.r.t. $\mathrm{Q}_{1}, \mathrm{Q}_{3}$, and $\mathrm{Q}_{5}$ respectively. The inverter output voltages across loads are $v_{\mathrm{AB}}$, $v_{\mathrm{BC}}$, and $v_{\mathrm{CA}}$.

An analysis of PS control of series resonant inverter is presented in [10]. Fig. 5 shows the inverter voltage waveform $\left(v_{\mathrm{AB}}\right)$ for the load-1 and load-1 current $\left(i_{1}\right)$ of the three-leg inverter. $v_{\mathrm{AB} 1}$ is the fundamental component of $v_{\mathrm{AB}}$. The current in the resonant tank is close to sine wave because of the filtering of harmonics by the LC resonant tank. Harmonics in load current waveforms are negligible. $\mathrm{I}_{1}, \mathrm{I}_{2}$, and $\mathrm{I}_{3}$ are the r.m.s values of the load currents.

In PS control, the peak value of $v_{\mathrm{AB} 1}$ is expressed as:

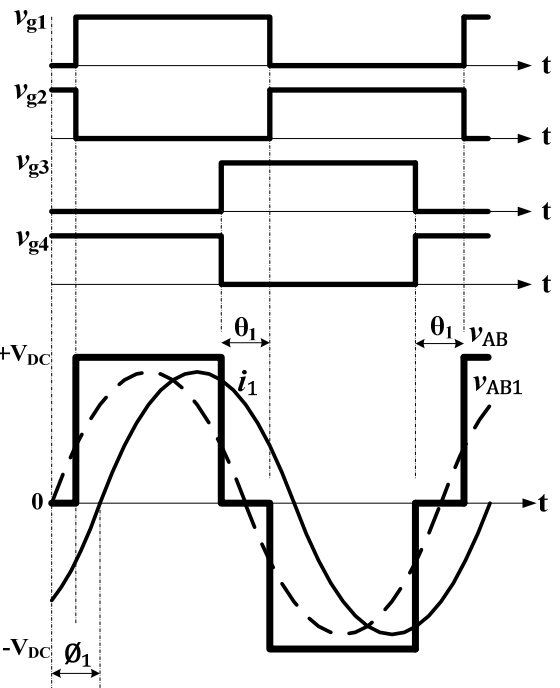

Fig. 5. Output voltage and current with control variables.

$$
\hat{v}_{\mathrm{AB} 1}=\frac{4 \mathrm{~V}_{\mathrm{dc}}}{\pi} \cos \frac{\theta_{1}}{2}
$$

$\widehat{\Gamma}_{1}$ is the peak amplitude of the load-1 current assumed sinusoidal, and $\emptyset_{1}$ is the power factor angle.

$$
\begin{aligned}
\widehat{\mathrm{I}}_{1} & =\frac{\hat{v}_{\mathrm{AB} 1}}{\left|z_{\text {eq }}\right|} \\
& =\frac{4 \mathrm{~V}_{\mathrm{DC}}}{\pi\left|\mathrm{Z}_{\text {eq }}\right|} \cos \frac{\theta_{1}}{2} \\
& =\frac{4 \mathrm{~V}_{\mathrm{DC}} \cos \emptyset_{1}}{\pi \mathrm{R}_{\text {eq }}} \cos \frac{\theta_{1}}{2}
\end{aligned}
$$

The output power of load-1 is expressed as:

$$
\begin{aligned}
\mathrm{P}_{\mathrm{o} 1} & =\frac{{\widehat{\mathrm{r}_{1}}}^{2}}{2} \mathrm{R}_{\mathrm{eq} 1} \\
& =\frac{8 \mathrm{~V}_{\mathrm{DC}} \cos ^{2} \emptyset_{1}}{\pi^{2} \mathrm{R}_{\text {eq } 1}} \cos ^{2} \frac{\theta_{1}}{2}
\end{aligned}
$$

$\mathrm{P}_{02}$ and $\mathrm{P}_{\mathrm{o} 3}$ are output powers of load-2 and load-3, respectively. The total output power $\left(\mathrm{P}_{\mathrm{T}}\right)$ is expressed as $\mathrm{P}_{\mathrm{T}}=\mathrm{P}_{\mathrm{o} 1}+\mathrm{P}_{\mathrm{o} 2}+\mathrm{P}_{\mathrm{o} 3}$.

The quality factor $(\mathrm{Q})$ for load-1 and normalized switching frequency $\left(\omega_{n}\right)$ are expressed as:

$$
\begin{aligned}
& \mathrm{Q}=\frac{\sqrt{\frac{\mathrm{L}_{\mathrm{r} 1}}{\mathrm{C}_{\mathrm{r}}}}}{\mathrm{R}_{\mathrm{eq}}} \\
& \omega_{\mathrm{n}}=\frac{\omega_{\mathrm{s}}}{\omega_{\mathrm{r} 1}} \text { and } \omega_{\mathrm{r} 1}=\frac{1}{\sqrt{\mathrm{L}_{\mathrm{r} 1} \mathrm{C}_{\mathrm{r} 1}}}
\end{aligned}
$$

where $\omega_{s}$ is angular switching frequency and $\omega_{r}$ is the angular resonant frequency.

From the above equations, the amplitude of the fundamental component of output voltage can be controlled by varying $\theta$. Consequently, the load current and output power also can be controlled by varying $\theta$.

From Fig. 4,

$$
\begin{aligned}
& \theta_{1}=180^{\circ}-\alpha_{1} \\
& \left(240^{\circ}+\theta_{2}\right)=\left(\alpha_{1}+180^{\circ}\right) \\
& \theta_{2}=\left(\alpha_{1}-60^{\circ}\right)=\left(120^{\circ}-\theta_{1}\right)
\end{aligned}
$$

From Eqs. (7) and (9),

$$
\mathrm{D}_{1}=\frac{180^{\circ}-\left|\theta_{1}\right|}{180^{\circ}}
$$




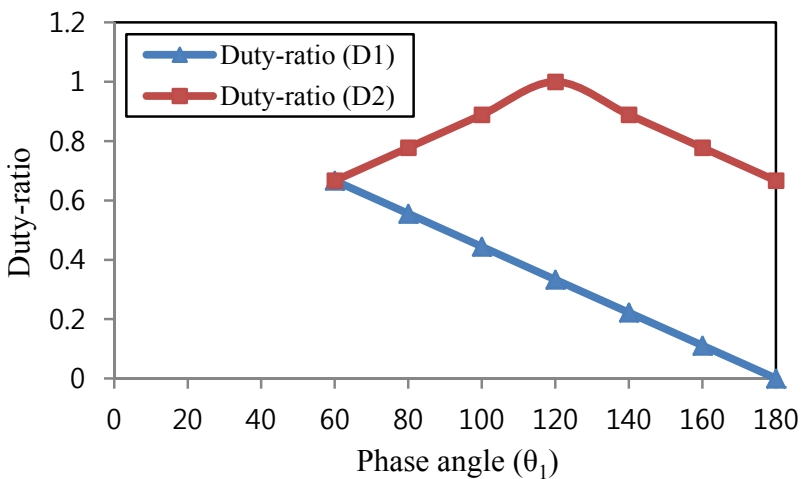

Fig. 6. Variation of duty-ratios vs. phase angle $\left(\theta_{1}\right)$.

$$
\mathrm{D}_{2}=\frac{180^{\circ}-\left|\theta_{2}\right|}{180^{\circ}}
$$

Eqs. (7) to (11) show that $D_{1}$ and $D_{2}$ are dependent on $\theta_{1}$ and $\theta_{2}$, respectively. These are in turn dependent on $\alpha_{1}$. Fig. 6 shows the variation of duty-ratios $\mathrm{D}_{1}$ and $\mathrm{D}_{2}$ w.r.t. phase angle $\left(\theta_{1}\right)$. As leg-2 is common for load-1 and load-2, the variation of $D_{1}$ results in the variation of $D_{2}$ in a certain manner, which is justified by Eq. (9). $\theta_{3}$ will not be affected because load- 3 is not connected to leg- 2 . Hence, $D_{3}$ will not change.

The output powers of load-1 to load-3 are proportional to $\cos ^{2} \frac{\theta_{1}}{2}, \cos ^{2} \frac{\theta_{2}}{2}$, and $\cos ^{2} \frac{\theta_{3}}{2}$, respectively. As $\frac{\theta_{1}}{2}$ varies from $30^{\circ}$ to $90^{\circ}, \frac{\theta_{2}}{2}$ varies from $30^{\circ}$ to $0^{\circ}$ and back to $30^{\circ}$. Hence $\cos ^{2} \frac{\theta_{1}}{2}$ varies from 0.75 to 0 and $\cos ^{2} \frac{\theta_{2}}{2}$ varies from 0.75 to 1 and back to 0.75 . Whereas, $\cos ^{2} \frac{\theta_{3}}{2}$ does not vary at all. Full range control of load- 1 power results in a $25 \%$ variation in load-2 power and no variation in load-3 power. In cooking applications, precise temperature control may not be very essential. This maximum variation of $25 \%$ in one of the loads when a particular load is controlled may not be a significant drawback.

\section{RESULTS OF THREE-LEG INVERTER CONFIGURATION}

The three-leg inverter configuration with the PSC technique is simulated and is experimentally verified using the parameters shown in Table I.

Fig. 7 shows the experimental set-up of a three-leg inverter configuration. Fig. 7(a) shows the induction heating loads with a 3-leg inverter circuit. Fig. 7(b) shows a 3-leg inverter circuit with a pulse generator and a driver circuit. In the control circuit, two UC3875 ICs are used for six control pulses with phase shift control. Three IR2110 ICs are used as drivers. The implementation of the control circuit is simple without any logic gates. This configuration is designed and operated at a switching frequency of $30 \mathrm{kHz}$.

Fig. 8 shows the switching pulses for a 3-leg inverter configuration. Fig. 8(a) shows the switching pulses for upper
TABLE I

PARAMETERS OF THREe-Leg INVERTER CONFIGURATION

\begin{tabular}{|c|c|c|}
\hline Item & Symbol & Value \\
\hline Source voltage & $\mathrm{V}_{\mathrm{DC}}$ & $30 \mathrm{~V}$ \\
\hline $\begin{array}{l}\text { Equivalent resistance of each } \\
\text { load }\end{array}$ & $\mathrm{R}_{\mathrm{eq}}$ & $1.95 \Omega$ \\
\hline $\begin{array}{c}\text { Parasitic series resistance of } \\
\text { IH each load coil }\end{array}$ & & $0.14 \Omega$ \\
\hline $\begin{array}{l}\text { Equivalent inductance of each } \\
\text { load }\end{array}$ & $\mathrm{L}_{\mathrm{r}}$ & $68 \mu \mathrm{H}$ \\
\hline $\begin{array}{c}\begin{array}{c}\text { Resonant capacitance of each } \\
\text { load }\end{array} \\
(\mathrm{EPCOS} \mathrm{B} 25834-\mathrm{F} 6104-\mathrm{M} 001) \\
{[(3 \times 0.1 \mu \mathrm{F})+(0.15 \mu \mathrm{F})=0.45 \mu \mathrm{F}]}\end{array}$ & $\mathrm{C}_{\mathrm{r}}$ & $0.45 \mu \mathrm{F}$ \\
\hline ESR for $0.15 \mu \mathrm{F}$ capacitor & & $24 \mathrm{~m} \Omega$ \\
\hline ESR for $0.1 \mu \mathrm{F}$ capacitor & & $33 \mathrm{~m} \Omega$ \\
\hline Delay time in each leg & $t_{d}$ & $450 \mathrm{nsec}$ \\
\hline $\begin{array}{l}\text { Resonant frequency of load } \\
\text { circuit }\end{array}$ & $\mathrm{f}_{\mathrm{r}}$ & $28.77 \mathrm{kHz}$ \\
\hline $\begin{array}{l}\text { Switching frequency of each } \\
\text { leg }\end{array}$ & $f_{s}$ & $30 \mathrm{kHz}$ \\
\hline MOSFETs used & IRFP4110PbF & $\begin{array}{l}100 \mathrm{~V}, \\
180 \mathrm{~A} \\
\end{array}$ \\
\hline IRFP4110PbF - $\mathrm{R}_{\mathrm{DS} \text { (on) }}$ & & $3.7 \mathrm{~m} \Omega$ \\
\hline
\end{tabular}

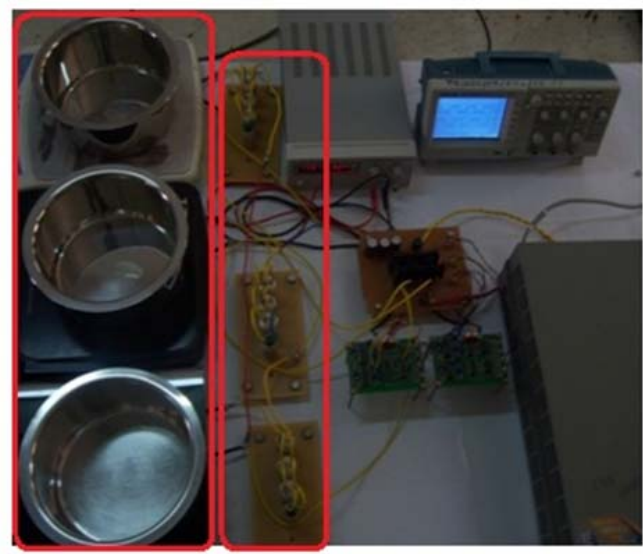

Induction Resonant
eating loads capacitors

(a)

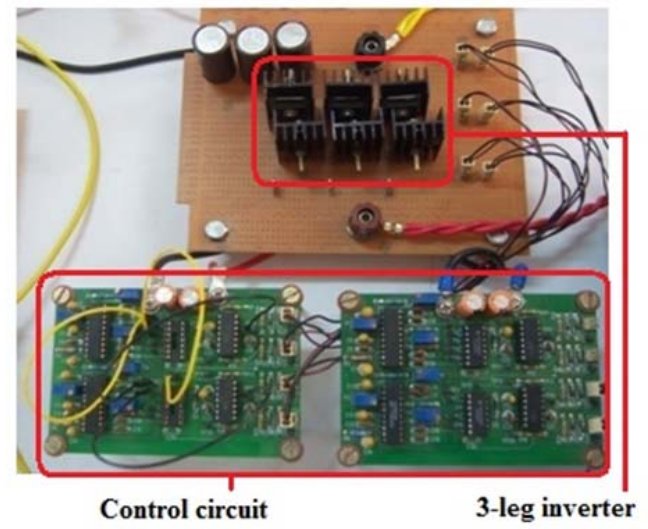

(b)

Fig. 7. Experimental set-up of the three-leg inverter configuration.

$a \quad$ Induction heating loads with inverter circuit

$b$ 3-leg inverter circuit with control circuit 


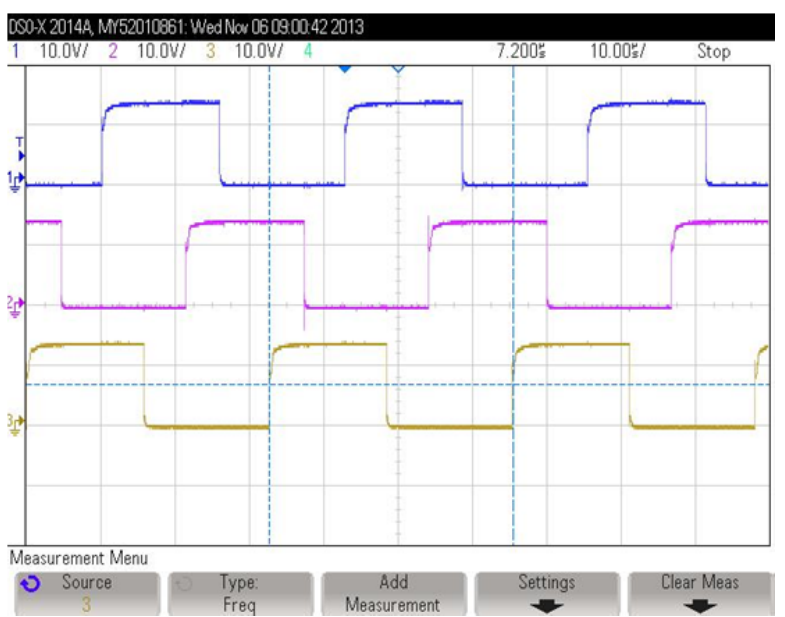

(a)

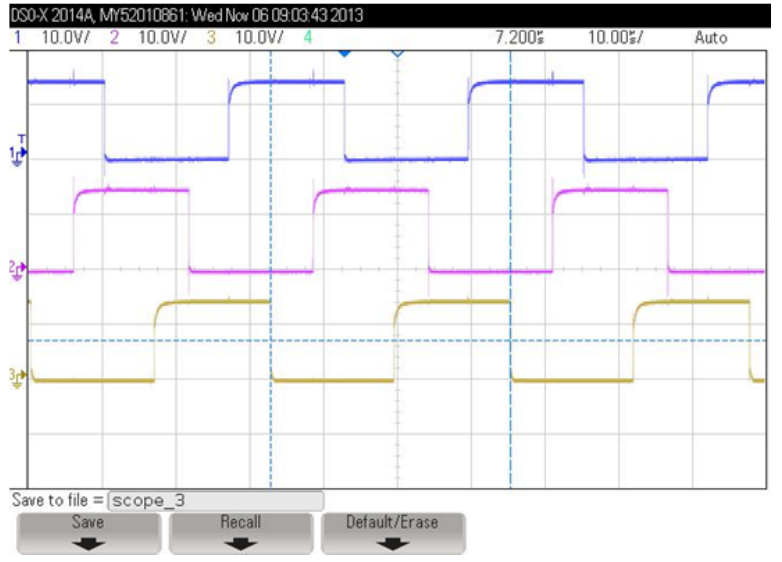

(b)

Fig. 8. Switching pulses for a three-leg inverter.

a Switching pulses for upper switching devices of each leg

$b \quad$ Switching pulses for lower switching devices of each leg

switching devices $\mathrm{Q}_{1}, \mathrm{Q}_{3}$, and $\mathrm{Q}_{5}$ of a 3-leg inverter. These pulses are $120^{\circ}$ phase shifted with each other. Fig. 8(b) shows the switching pulses for lower switching devices $\mathrm{Q}_{2}, \mathrm{Q}_{4}$, and $\mathrm{Q}_{6}$. These pulses are also $120^{\circ}$ phase shifted with each other and $180^{\circ}$ phase shifted with their respective upper switching device pulses.

All three loads are connected in delta. In addition, each load can be viewed as if connected to a full-bridge inverter. Each leg of the inverter is common for two loads. Under equal output power of all three loads, each output voltage is phase shifted from the other output voltage by $120^{\circ}$. Each load current is $120^{\circ}$ phase shifted from one another. For the control of each load power $\theta_{1}, \theta_{2}$, and $\theta_{3}$ can be controlled. Simulation and experimental results are shown in Figs. 9 to 10 for different PS combinations between leg-1 and leg- 2 . The load-1 current can be controlled by varying the phase angle $\left(\theta_{1}\right)$. Similarly, the load-2 current can be controlled by varying the phase angle $\left(\theta_{2}\right)$. For control of the load-3 current, phase angle $\left(\theta_{3}\right)$ is varied.

Fig. 9 shows the simulation waveforms. Fig. 9(a) shows the inverter output voltage of load-1 and its load current

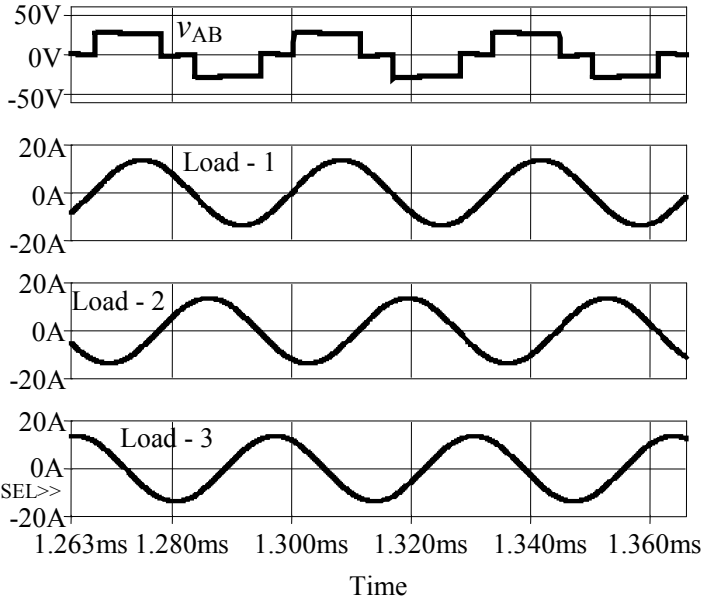

(a)

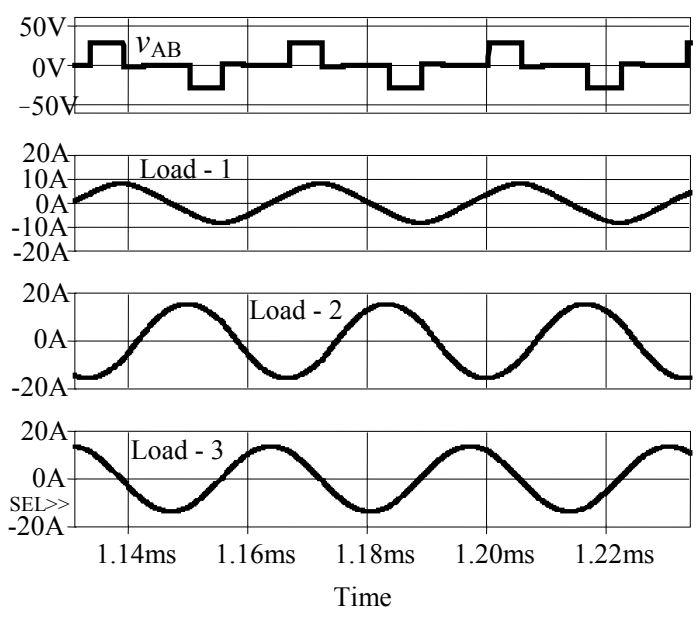

(b)

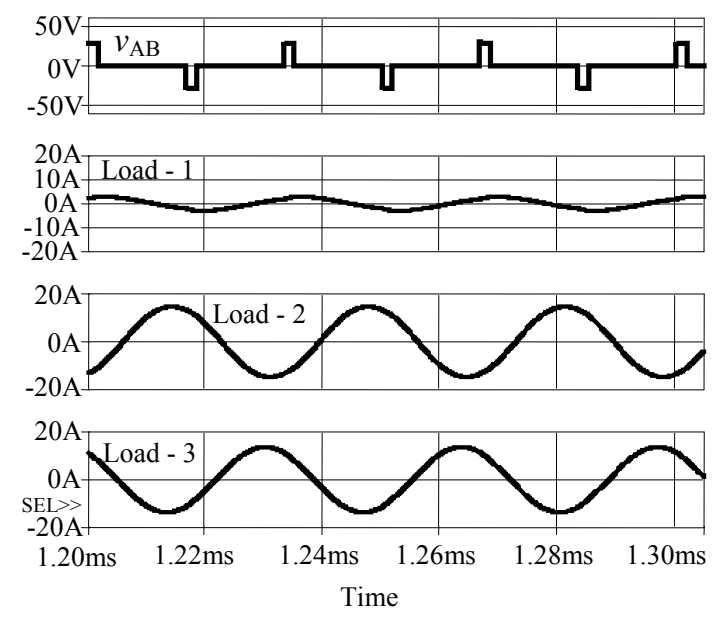

(c)

Fig. 9. Voltage waveform simulations across load-1 with all load currents.

$a$ at $\theta_{1}=60^{\circ} ; b$ at $\theta_{1}=120^{\circ} ; c$ at $\theta_{1}=160^{\circ}$

along with other two loads at $\theta_{1}=60^{\circ}$. Fig. 9(b) shows these waveforms at $\theta_{1}=120^{\circ}$. Fig. 9 (c) shows these waveforms at $\theta_{1}=160^{\circ}$. 


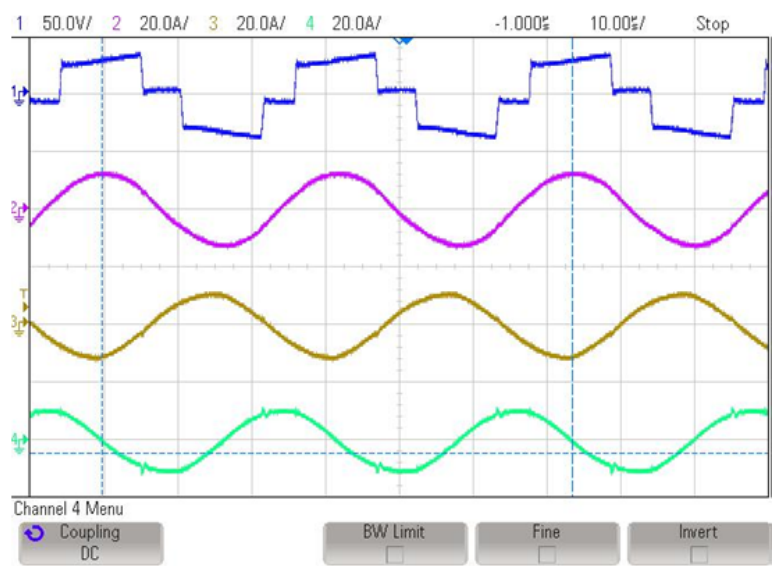

(a)

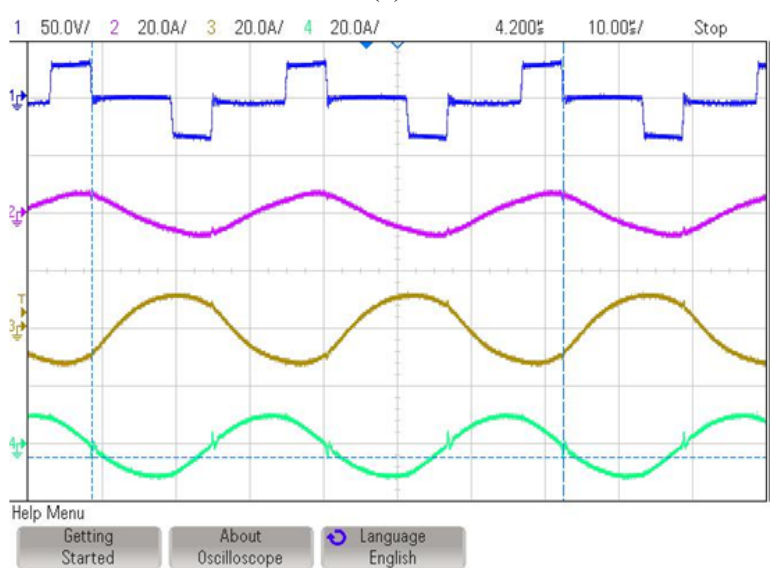

(b)

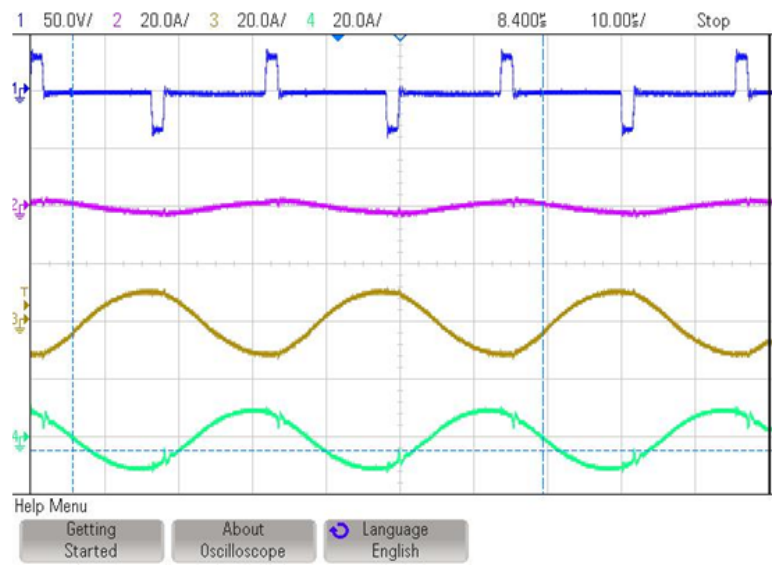

(c)

Fig. 10. Experimental voltage waveforms across load-1 and all load currents.

$a$ at $\theta_{1}=60^{\circ} ; b$ at $\theta_{1}=120^{\circ}$; cat $\theta_{1}=160^{\circ}$

Fig. 10 shows the experimental waveforms. Fig. 10(a) shows the inverter output voltage across load-1 and its load current along with other two loads at $\theta_{1}=60^{\circ}$. Fig. 10(b) shows these waveforms at $\theta_{1}=120^{\circ}$. Fig. 9(c) shows these waveforms at $\theta_{1}=160^{\circ}$.

Both simulation and experimental results are in good agreement with each other. This configuration can power three loads simultaneously with constant switching

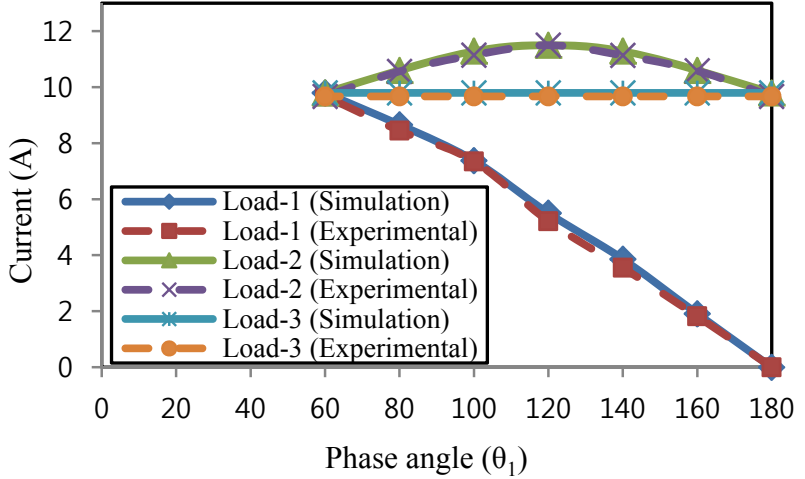

Fig. 11. Variation of load currents vs. phase angle $\left(\theta_{1}\right)$.

frequency.

In addition, any one-load current can be controlled using the PS control technique, which gives an almost independent power control of that load. In Figs. 9(a) to (c) and 10(a) to (c), the phase angle $\left(\theta_{1}\right)$ of load- 1 is taken as $60^{\circ}, 120^{\circ}$ and $160^{\circ}$. Hence, the corresponding load-1 current is controlled by phase angle $\left(\theta_{1}\right)$. The current in load- 2 varies because of the variation in $\theta_{1}$, as shown in Fig. 11 . With an increase in $\theta_{1}$, the current in load-2 initially increases, reaching a peak, and then decreases. Hence, there is little variation in load-2 current when load-1 current is controlled. Load-3 current remains constant because its phase angle $\left(\theta_{3}\right)$ remains constant at $60^{\circ}$.

In induction cooking applications, this small variation of the load-2 current may be tolerable as precise temperature control is not required. This configuration gives the advantage of power control of the required load, and reduces components count and offers one leg / load.

Switching devices of 3-leg inverter configuration have ZVS at low phase angles( $\theta)$ with PS control technique; switching devices may not have ZVS at higher phase angles $(\theta)$, which is the limitation of this configuration.

\section{CONTROL OF LOAD POWER}

In a 3-leg inverter configuration, required load power control can be achieved using the PS control technique. Each load power is dependent on corresponding load currents. Load currents are controlled with their phase angles $(\theta)$ and are experimentally verified. Load current magnitudes w.r.t. and their phase angles $(\theta)$ are shown in Table II.

The above table shows that when $\theta_{1}$ varies, load- 1 current is controlled. Load-2 current is slightly affected and load-3 current remains constant. The small variation of load-2 current may not be significant for cooking application. Similarly, the load- 2 current can be controlled by varying $\theta_{2}$ and the load- 3 current can be controlled by varying $\theta_{3}$. All load currents are in r.m.s. values under the experimental condition. 
TABLE II

LoAD CURRENTS vs. ITS Phase Angle $(\theta)$

\begin{tabular}{c|c|c|c|c|c|c}
\hline S. No & $\theta_{\mathbf{1}}$ & $\begin{array}{c}\text { Load-1 } \\
\text { current }\end{array}$ & $\theta_{\mathbf{2}}$ & $\begin{array}{c}\text { Load-2 } \\
\text { current }\end{array}$ & $\theta_{\mathbf{3}}$ & $\begin{array}{c}\text { Load-3 } \\
\text { current }\end{array}$ \\
\hline 1 & $60^{\circ}$ & $9.673 \mathrm{~A}$ & $60^{\circ}$ & $9.673 \mathrm{~A}$ & $60^{\circ}$ & $9.673 \mathrm{~A}$ \\
\hline 2 & $80^{\circ}$ & $8.449 \mathrm{~A}$ & $40^{\circ}$ & $10.567 \mathrm{~A}$ & $60^{\circ}$ & $9.673 \mathrm{~A}$ \\
\hline 2 & $100^{\circ}$ & $7.491 \mathrm{~A}$ & $20^{\circ}$ & $11.147 \mathrm{~A}$ & $60^{\circ}$ & $9.673 \mathrm{~A}$ \\
\hline 3 & $120^{\circ}$ & $5.216 \mathrm{~A}$ & $0^{\circ}$ & $11.5 \mathrm{~A}$ & $60^{\circ}$ & $9.673 \mathrm{~A}$ \\
\hline 4 & $140^{\circ}$ & $3.55 \mathrm{~A}$ & $20^{\circ}$ & $11.135 \mathrm{~A}$ & $60^{\circ}$ & $9.673 \mathrm{~A}$ \\
\hline 5 & $160^{\circ}$ & $1.821 \mathrm{~A}$ & $40^{\circ}$ & $10.585 \mathrm{~A}$ & $60^{\circ}$ & $9.673 \mathrm{~A}$ \\
\hline 6 & $180^{\circ}$ & $0 \mathrm{~A}$ & $60^{\circ}$ & $9.673 \mathrm{~A}$ & $60^{\circ}$ & $9.673 \mathrm{~A}$ \\
\hline 7 & $60^{\circ}$ & $9.673 \mathrm{~A}$ & $80^{\circ}$ & $8.449 \mathrm{~A}$ & $40^{\circ}$ & $10.567 \mathrm{~A}$ \\
\hline 8 & $60^{\circ}$ & $9.673 \mathrm{~A}$ & $100^{\circ}$ & $7.491 \mathrm{~A}$ & $20^{\circ}$ & $11.147 \mathrm{~A}$ \\
\hline 9 & $60^{\circ}$ & $9.673 \mathrm{~A}$ & $120^{\circ}$ & $5.216 \mathrm{~A}$ & $0^{\circ}$ & $11.5 \mathrm{~A}$ \\
\hline 10 & $60^{\circ}$ & $9.673 \mathrm{~A}$ & $140^{\circ}$ & $3.55 \mathrm{~A}$ & $20^{\circ}$ & $11.135 \mathrm{~A}$ \\
\hline 11 & $60^{\circ}$ & $9.673 \mathrm{~A}$ & $160^{\circ}$ & $1.821 \mathrm{~A}$ & $40^{\circ}$ & $10.585 \mathrm{~A}$ \\
\hline 12 & $60^{\circ}$ & $9.673 \mathrm{~A}$ & $180^{\circ}$ & $0 \mathrm{~A}$ & $60^{\circ}$ & $9.673 \mathrm{~A}$ \\
\hline 13 & $40^{\circ}$ & $10.567 \mathrm{~A}$ & $60^{\circ}$ & $9.673 \mathrm{~A}$ & $80^{\circ}$ & $8.449 \mathrm{~A}$ \\
\hline 14 & $20^{\circ}$ & $11.147 \mathrm{~A}$ & $60^{\circ}$ & $9.673 \mathrm{~A}$ & $100^{\circ}$ & $7.491 \mathrm{~A}$ \\
\hline 15 & $0^{\circ}$ & $11.5 \mathrm{~A}$ & $60^{\circ}$ & $9.673 \mathrm{~A}$ & $120^{\circ}$ & $5.216 \mathrm{~A}$ \\
\hline 16 & $20^{\circ}$ & $11.135 \mathrm{~A}$ & $60^{\circ}$ & $9.673 \mathrm{~A}$ & $140^{\circ}$ & $3.55 \mathrm{~A}$ \\
\hline 17 & $40^{\circ}$ & $10.585 \mathrm{~A}$ & $60^{\circ}$ & $9.673 \mathrm{~A}$ & $160^{\circ}$ & $1.821 \mathrm{~A}$ \\
\hline 18 & $60^{\circ}$ & $9.673 \mathrm{~A}$ & $60^{\circ}$ & $9.673 \mathrm{~A}$ & $180^{\circ}$ & $0 \mathrm{~A}$ \\
\hline
\end{tabular}

TABLE III

LoAd-1 Output Power vs. its Phase Angle $\left(\theta_{1}\right)$

\begin{tabular}{c|c|c}
\hline S. No & $\theta_{\mathbf{1}}$ (degree) & Output power (watts) \\
\hline 1 & $0^{\circ}$ & 257.89 \\
\hline 2 & $20^{\circ}$ & 241.78 \\
\hline 3 & $40^{\circ}$ & 218.48 \\
\hline 4 & $60^{\circ}$ & 182.46 \\
\hline 5 & $80^{\circ}$ & 139.2 \\
\hline 6 & $100^{\circ}$ & 109.42 \\
\hline 7 & $120^{\circ}$ & 53.05 \\
\hline 8 & $140^{\circ}$ & 24.57 \\
\hline 9 & $160^{\circ}$ & 6.47 \\
\hline 10 & $180^{\circ}$ & 0
\end{tabular}

Fig. 11 shows load currents versus $\theta_{1}$. For a variation of $\theta_{1}$ from $60^{\circ}$ to $180^{\circ}$, its load current varies from $9.673 \mathrm{~A}$ to $0 \mathrm{~A}$. Under this condition, load-2 current has small variation, as leg-2 is common for load-1 and load-2. Under this variation of $\theta_{1}, \theta_{2}$ varies from $60^{\circ}$ to $0^{\circ}$ and back to $60^{\circ}$. However, $\theta_{3}$ is remains constant at $60^{\circ}$. Each load current magnitude depends upon its load PS angle $(\theta)$. Simulation and experimental results are in good agreement with each other. Load-1 output power w.r.t. its phase angle $(\theta)$ is shown in Table III.

Fig. 12 shows the overall efficiency versus $\theta_{1}$. Overall efficiency for this configuration is $>93 \%$ for the entire control range of one load. Total output power is measured by adding the individual load outputs. Each load output is computed as $I^{2} R_{\text {eq. ' }} \mathrm{I}$ ' is the r.m.s. value of the respective load current. ' $R_{\text {eq }}$ ' is the equivalent load resistance of the respective load. Input power is obtained by multiplication of DC input voltage and average input current of the inverter.

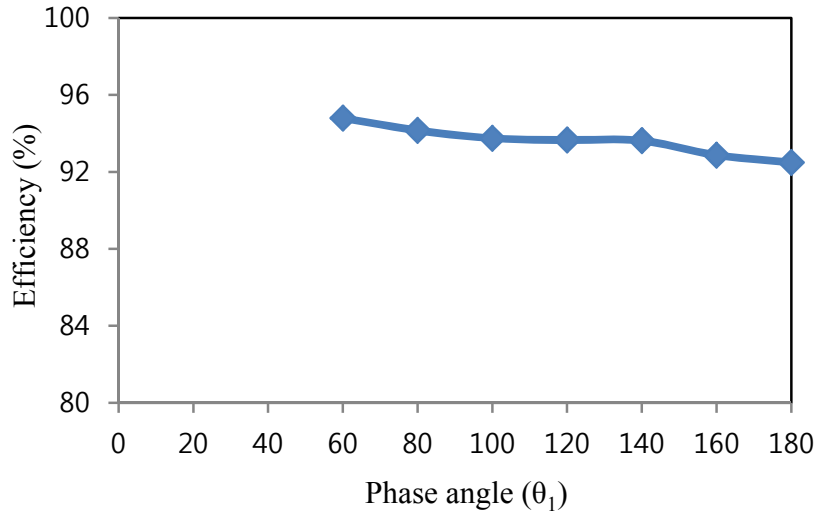

Fig. 12. Overall efficiency vs. phase angle $\left(\theta_{1}\right)$.

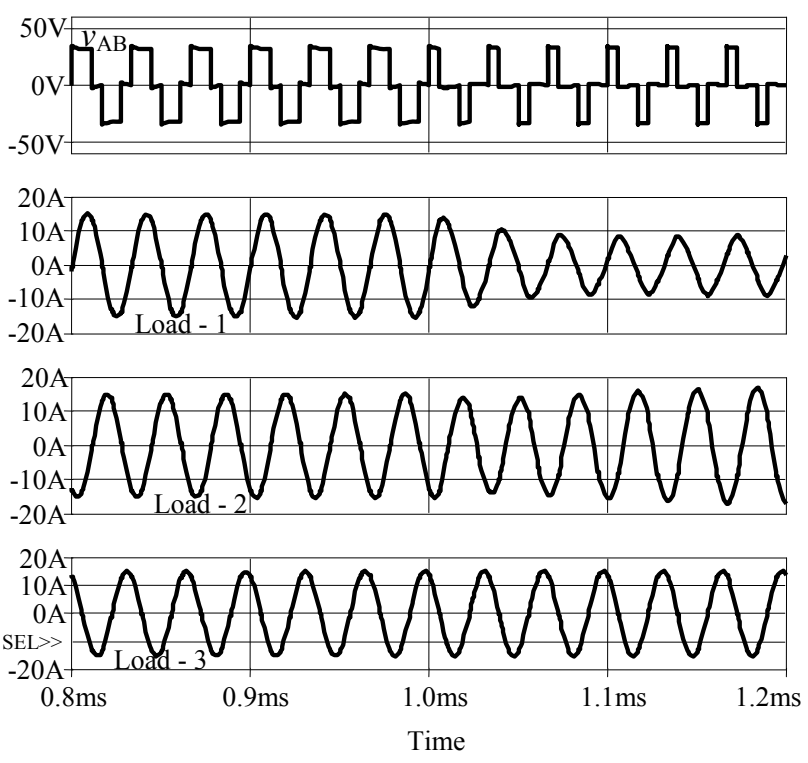

Fig. 13. Transient variation of all load currents for sudden variation in $\mathrm{D}_{1}$.

Fig. 13 shows the transient variation of all load currents for sudden variation in $\mathrm{D}_{1}$ at $1 \mathrm{msec}$. Load- 1 and load- 2 currents have smooth transition to new steady state condition. Load-3 current is not affected.

From Eq. (7),

$$
\begin{aligned}
& \theta_{1}=180^{\circ}-\alpha_{1} \\
& \text { Similarly, } \theta_{2}=180^{\circ}-\alpha_{2} \\
& \theta_{3}=180^{\circ}-\alpha_{3}
\end{aligned}
$$

$\alpha_{1}$ and $\alpha_{2}$ are controlled independently and $\alpha_{3}$ is dependent on $\alpha_{1}$ and $\alpha_{2}$.

$$
\begin{array}{cc}
\alpha_{3}=\left(\alpha_{1}+\alpha_{2}\right) & \text { up to }\left(\alpha_{1}+\alpha_{2}\right) \leq 180^{\circ} \\
\alpha_{3}=360^{\circ}-\left(\alpha_{1}+\alpha_{2}\right) & \text { for }\left(\alpha_{1}+\alpha_{2}\right)>180^{\circ}
\end{array}
$$

Fig. 14 shows each load power control possibility in combination of all loads w.r.t. their $\alpha$. In Fig. 14, X represents $\alpha_{1}$ for load-1, Y represents $\alpha_{2}$ for load-2, and Z represents $\alpha_{3}$ for load-3. When $\alpha$ value is $0^{\circ}$, the load power is also zero. When $\alpha$ value changes from $0^{\circ}$ to $180^{\circ}$, the load power changes from zero to maximum. Simultaneously, all loads can have equal maximum power for $\alpha_{1}=\alpha_{2}=\alpha_{3}=120^{\circ}$ i.e., respective $\theta$ values are $60^{\circ}$ each. For different combinations 


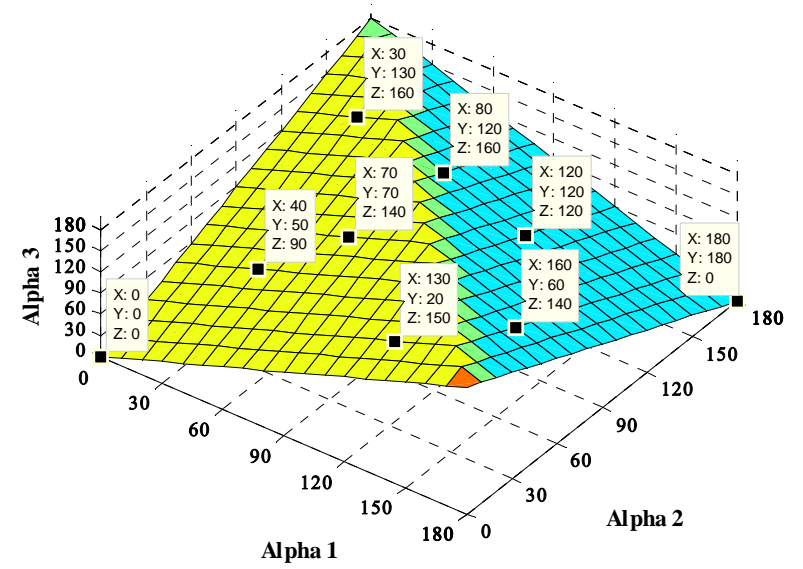

Fig. 14. Each load power control possibilities vs. their $\alpha$.

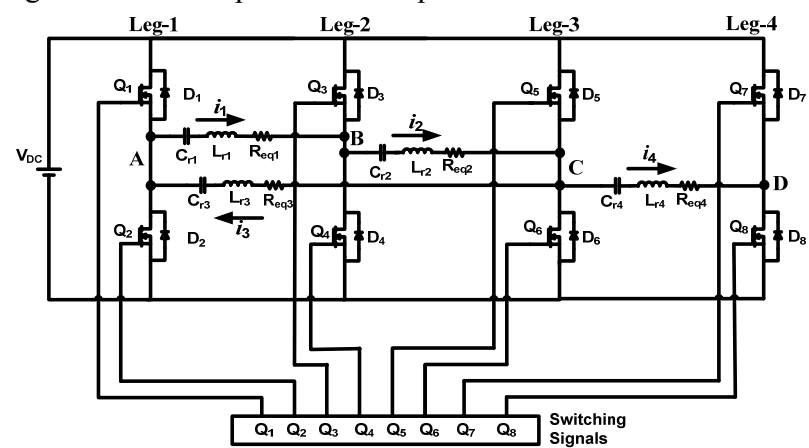

(a)

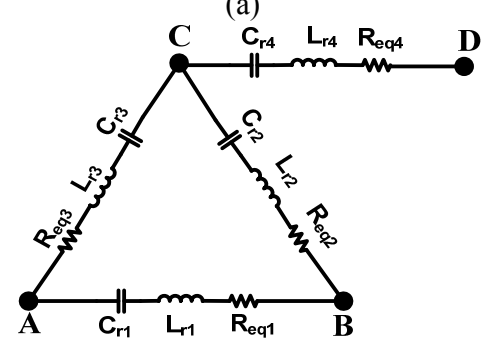

(b)

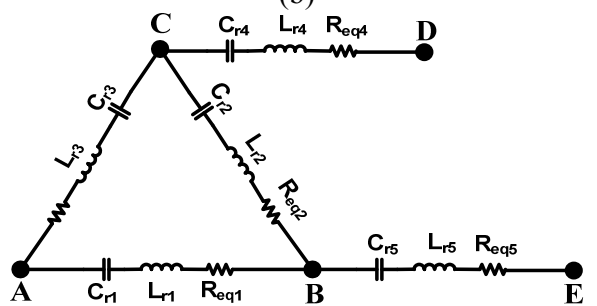

(c)

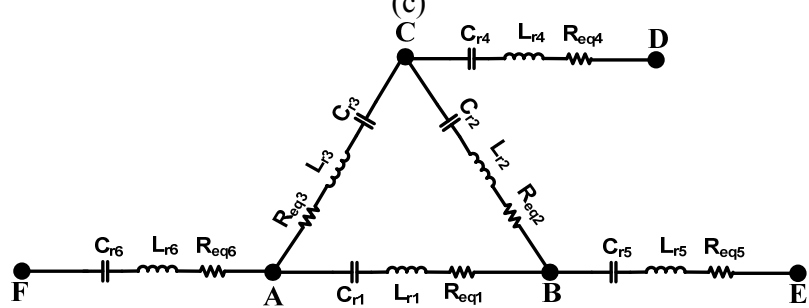

(d)

Fig. 15. Extension of the three-leg inverter configuration to multiple loads.

a Extension of three-leg inverter configuration to four-leg configuration;

$b$ Four load resonant circuit; $c$ Five load resonant circuit;

d Six load resonant circuit of individual load powers, a look-up table can be made with possible values of $\alpha$ for wide operating flexibility.

\section{EXTENSION OF THREE-LEG INVERTER CONFIGURATION}

This configuration requires two switching devices per load or one leg per load, and is extended for multiple loads as shown in Fig. 15.

In Fig. 15(a), a three-leg configuration is extended for four loads by adding an additional leg to the right of leg-3. The switching frequency is same for the existing configuration. By controlling this load with the PS control technique, the load connected between leg-3 and this additional leg-4 can be independently controlled. Here also, the number of legs per load is one. Fig. 15(b) shows only load resonant circuits where three loads are connected in delta across the inverter output voltages $v_{\mathrm{AB}}, v_{\mathrm{BC}}$, and $v_{\mathrm{CA}}$, respectively, and an addition of fourth load is across the inverter output voltage $v_{\mathrm{CD}}$. Extension to fifth and sixth load is shown in Figs. 15(c) and (d) respectively. Independent control of fifth and sixth loads are possible with PS control technique. Hence, this method can be extended to six loads also with a number of legs per load equal to one.

\section{CONCLUSION}

A three-leg inverter configuration with three loads for induction cooking applications has been presented. In this configuration, the required load can be controlled almost independently, and can be extended for more loads. The number of switching devices per load is two (i.e., one leg per load). Constant switching frequency is used for powering the loads. Each load is operated at a switching frequency of $30 \mathrm{kHz}$. PS control technique is used for the power control of the required load. The design and output power control of this configuration is simple. This configuration can also be used for uniform surface heating with a minimum components count. The simulation and experimental results of this configuration are in good agreement.

\section{REFERENCES}

[1] S. M. W. Ahmed, M. M. Eissa, M. Edress, and T. S. Abdel-Hameed, "Experimental investigation of full bridge series resonant inverters for induction-heating cooking appliances," 4th IEEE Conference on Industrial Electronics and Applications, ICIEA 2009, pp.3327-3332, 2009.

[2] M. Miyamae, T. Ito, K. Matsuse, and M. Tsukahara, "Performance of a high frequency quasi-resonant inverter with variable-frequency output for induction heating," IEEE 7th International Power Electronics and Motion Control Conference, 2012.

[3] A. Fujita, H. Sadakata, I. Hirota, H. Omori, and M. Nakaoka, "Latest developments of high-frequency series 
load resonant inverter type built-in cooktops for induction heated all metallic appliances," IPEMC' 2009, pp. 2537-2544, 2009.

[4] N. A. Ahmed and M. Nakaoka, "Boost-half-bridge edge resonant soft switching PWM high-frequency inverter for consumer induction heating appliances," IEE Electric Power Applications, Vol. 153, No. 6, pp. 932-938, Nov. 2006.

[5] O. Jimenez, O. Lucia, I. Urriza, L. A. Barragan, and D. Navarro, "Design and evaluation of a low-cost high-performance $\Sigma-\Delta \mathrm{ADC}$ for embedded control systems in induction heating appliances," IEEE Trans. Ind. Electron., Vol. 61, No. 5, pp. 2601-2611, May 2014.

[6] H. Sarnago, O. Lucia, A. Mediano, and J. M. Burdio, "Direct AC-AC resonant boost converter for efficient domestic induction heating applications," IEEE Trans. Power Electron., Vol. 29, No. 3, pp. 1128-1139, Mar. 2014.

[7] I. Millan, J. M. Burdío, J. Acero, O. Lucía, and S. Llorente, "Series resonant inverter with selective harmonic operation applied to all-metal domestic induction heating," IET Trans. Power Electron., Vol. 4, No. 5, pp. 587-592, May 2011.

[8] L. Meng, K. W. E. Cheng, and K. W. Chan, "Systematic approach to high-power and energy-efficient industrial induction cooker system: circuit design, control strategy, and prototype evaluation," IEEE Trans. Power Electron., Vol. 26, No. 12, pp. 3754-3765, Dec. 2011.

[9] J. Shen, H. Ma,W. Yan, J. Hui, and L. Wu, "PDM and PSM hybrid power control of a series-resonant inverter for induction heating applications," IEEE Conference on Industrial Electronics and Applications (ICIEA), 2006.

[10] J. M. Burdio, L. A. Barragan, F. Monterde, D. Navarro, and J. Acero, "Asymmetrical voltage cancellation control for full-bridge series resonant inverters," IEEE Trans. Power Electronics, Vol. 19, No. 2, pp. 461-469, Mar. 2004.

[11] H. Sarnago, O. Lucia, A. Mediano, and J. M. Burdio, "Class D/DE dual-mode operation resonant converter for improved efficiency domestic induction heating system," IEEE Trans. Power Electron., Vol. 28, No. 3, pp. 1274-1285, Mar. 2013.

[12] F. Forest, E. Laboure, F. Costa, and J. Y. Gaspard, "Principle of a multi-load / single converter system for low power induction heating," IEEE Trans. Power Electron., Vol. 15, No. 2, pp. 223-230, Mar. 2000.

[13] J. M. Burdio, F. Monterde, J. R. Garcia, L. A. Barragan, and A. Martinez, "A two-output series-resonant inverter for induction-heating cooking appliances," IEEE Trans. Power Electron., Vol. 20, No. 4, pp. 815-822, Jul. 2005.

[14] S. Zenitani, M. Okamoto, E. Hiraki, and T. Tanaka, "A charge boost type multi output full bridge high frequency soft switching inverter for IH cooking appliance," 14th International Power Electronics and Motion Control Conference (EPE-PEMC), pp. T2-127 - T2-133, 2010.

[15] O. Lucia, J. M. Burdio, I. Millan, J. Acero, D. Puyal, "Load-adaptive control algorithm of half-bridge series resonant inverter for domestic induction heating," IEEE Trans. Ind. Electron., Vol. 56, No. 8, pp. 3106-3116, Aug. 2009.

[16] O. Lucia, J. M. Burdio, L. A. Barragan, C. Carretero, and J. Acero, "Series resonant multi-inverter with discontinuous-mode control for improved light-load operation," IEEE Trans. Ind. Electron., Vol. 58, No. 11, pp. 5163-5171, Nov. 2011.
[17] O. Lucia, I. Urriza, Luis A. Barragan, D. Navarro, O. Jimenez, and J. M. Burdio, "Real time FPGA-based hardware in the loop simulation test bench applied to multiple output power converters," IEEE Trans. Ind. Appl., Vol. 47, No. 2, pp. 853-860, Mar./Apr. 2011.

[18] O. Lucia, C. Carretero, J. M. Burdio, J. Acero, and F. Almazan, "Multiple-output resonant matrix converter for multiple induction heaters," IEEE Trans. Ind. Appl., Vol. 48, No. 4, pp. 1387-1396, Jul./Aug. 2012.

[19] I. Sheikhian, N. Kaminski, S. Vob, W. Scholz, and E. Herweg, "Optimisation of the reverse conducting IGBT for zero-voltage switching applications such as induction cookers," IET Trans. Circuits, Devices \& Syst., Vol. 8, No. 3, pp. 176-181, May 2014.

[20] V. M. Primiani, S. Kovyryalov, and G. Cerri, "Rigorous electromagnetic model of an induction cooking system," IET Trans. Science, Meas. \& Technol., Vol. 6, No. 4, pp. 238-246, Jul. 2012.

[21] C. Carretero, O. Lucia, J. Acero, R. Alonso, and J. M. Burdio, "Frequency-dependent modelling of domestic induction heating systems using numerical methods for accurate time-domain simulation," IET Trans. Power Electron., Vol. 5, No. 8, pp. 1291-1297, Sep. 2012.

[22] L. C. Meng, K. W. E. Cheng, K. W. Chan, and Y. Lu, "Variable turn pitch coils design for heating performance enhancement of commercial induction cooker," IET Trans. Power Electron., Vol. 5, No. 1, pp. 134-141, Jan. 2012.

[23] J. Acero, C. Carretero, R. Alonso, and J. M. Burdio, "Quantitative evaluation of induction efficiency in domestic induction heating applications," IEEE Trans. Magn., Vol. 49, No. 4, pp. 1382-1389, Apr. 2013.

[24] J. Acero, C. Carretero, I. Millan, O. Lucia, R. Alonso, and J. M. Burdio, "Analysis and modeling of planar concentric windings forming adaptable-diameter burners for induction heating appliances," IEEE Trans. Power Electron., Vol. 26, No. 5, pp. 1546-1558, May 2011.

[25] O. Jimenez, O. Lucia, I. Urriza, L. A. Barragan, P. Mattavelli, and D. Boroyevich, "An FPGA-based gain-scheduled controller for resonant converters applied to induction cooktops," IEEE Trans. Power Electron., Vol. 29, No. 4, pp. 2143-2152, Apr. 2014.

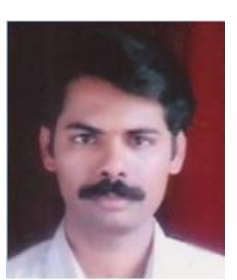

P. Sharath Kumar received a B.Tech degree in Electrical and Electronics Engineering from Jawaharlal Nehru Technological University, Hyderabad, India in 2006 and a M.Tech degree from the National Institute of Technology, Kurukshetra, India in 2008. He is presently pursuing a Ph.D. in Electrical Engineering at the National Institute of Technology, Warangal, India. His area of interest is high frequency resonant inverters for induction cooking and LED lighting applications.

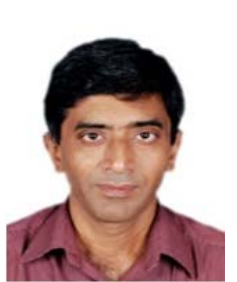

N. Vishwanathan received a B.Sc (Engg.) degree in electrical engineering from Dayalbagh Educational Institute, Agra, India, in 1990, a M.Tech. degree in electrical machines and industrial drives from REC, Warangal, India in 1992, and a Ph.D. from Indian Institute of Science, Bangalore, India, in 2004. He is currently working as a Professor in the Dept. of Electrical Engg., NIT, Warangal, India. His areas of interest are switched mode power conversion and induction heating applications. 


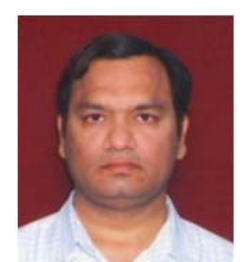

Bhagwan K. Murthy obtained his B.E.

(Electrical) and M.E. (Industrial Electronics) degrees from the M. S. University of Baroda, India in 1983 and 1987, respectively. He did his Ph.D. at IIT Madras in 1999. He is

working as Professor of Electrical

Engineering at the National Institute of

Technology, Warangal, India. His research interests include application of power electronics to DSP controlled industrial drives and renewable energy. 